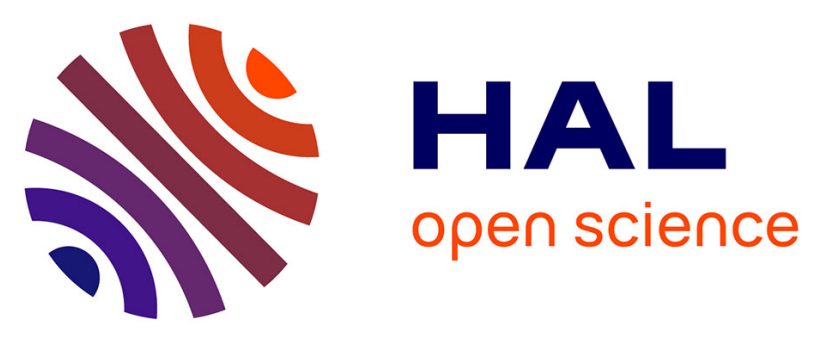

\title{
Record of trace organic contaminants in a river sediment core: from historical wastewater management to historical use
}

Thomas Thiebault, Fabrice Alliot, Thierry Berthe, Hélène Blanchoud, Fabienne Petit, Elodie Guigon

\section{To cite this version:}

Thomas Thiebault, Fabrice Alliot, Thierry Berthe, Hélène Blanchoud, Fabienne Petit, et al.. Record of trace organic contaminants in a river sediment core: from historical wastewater management to historical use. Science of the Total Environment, 2021, 773, pp.145694. 10.1016/j.scitotenv.2021.145694 . insu-03134012

\section{HAL Id: insu-03134012 https://hal-insu.archives-ouvertes.fr/insu-03134012}

Submitted on 8 Feb 2021

HAL is a multi-disciplinary open access archive for the deposit and dissemination of scientific research documents, whether they are published or not. The documents may come from teaching and research institutions in France or abroad, or from public or private research centers.
L'archive ouverte pluridisciplinaire $\mathbf{H A L}$, est destinée au dépôt et à la diffusion de documents scientifiques de niveau recherche, publiés ou non, émanant des établissements d'enseignement et de recherche français ou étrangers, des laboratoires publics ou privés. 


\section{Record of trace organic contaminants in a river sediment core: from} historical wastewater management to historical use

Thomas Thiebault $\mathrm{a}^{\mathrm{a}}$, Fabrice Alliot ${ }^{\mathrm{a}}$, Thierry Berthe ${ }^{\mathrm{b}}$, Hélène Blanchoud ${ }^{\mathrm{a}}$, Fabienne Petit ${ }^{\mathrm{b}}$, Elodie Guigon $^{\mathrm{a}}$

${ }^{\text {a }}$ EPHE, PSL University, UMR 7619 METIS Sorbonne University, CNRS, EPHE, F-75005, 4 place Jussieu, Paris, France

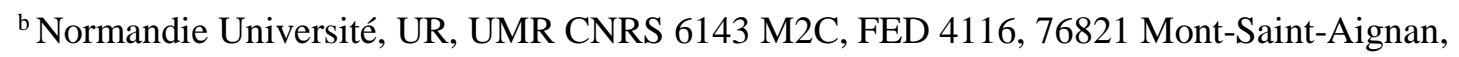
*To whom correspondence should be addressed. E-mail: thomas.thiebault@ephe.psl.eu Phone: +33 (0) 144275997

\section{Abstract}

Some trace organic contaminants (TrOCs) can be considered as ubiquitous contaminants since the 1950s, and the study of their historical distribution within river sediments allows us to better understand the temporal variation of the chemical quality of sediments, and make assumptions about the most insightful forcings impacting these distributions. In this study, the occurrence of 41 TrOCs of various classes (i.e. pharmaceutical products and pesticides) was studied in a sedimentary core sampled in a disused dock along the Seine River, France. This core covers a 60 year-long period between 1944 and 2003, and 23 TrOCs were detected at least once. Their concentrations mainly ranged between 1 and 10 ng g $^{-1}$ within the core, except for tetracycline that exhibited higher concentrations ( hundreds of ng. $\mathrm{g}^{-1}$ ). The dating of the core, based on previous studies, enabled the characterization of the changes since 1945, potentially impacted by (i) the sewer connectivity, (ii) the upgrading of wastewater treatment technologies, (iii) historical modifications in the use of each TrOC, and (iv) the sedimentary composition. In every case the deepest occurrence of each TrOC in the core matched its market authorization date, indicating the potential of TrOC to be used as chronomarkers. This study also reveals that the recent upgrading of wastewater treatment technologies within the 
watershed decreased the concentrations of each TrOC, despite an increase in TrOC diversity in the most recent years.

\section{Keywords}

Sediments, Wastewater treatment, Trace Organic Contaminants, Pharmaceuticals, Pesticides

\section{Introduction}

Since WWII, a large number of trace organic contaminants (TrOCs) have been regularly launched on the market for different uses (Bernhardt et al., 2017), e.g. pharmaceutical products, crop protection products, and personal care products. These contaminants are generally classified as contaminants of emerging concern, meaning that their detection in environmental compartments is "recent" and raises serious issues about their ecotoxicological impact (Daughton, 2004; Välitalo et al., 2017).

Moreover, as no environmental impact evaluation was performed prior to market launch (until a pesticide directive by the European Commission ( 1991a)), a significant and growing number of TrOCs (as main products or metabolites) have been detected in numerous environmental compartments, for example since the 1960s and 1970s for some pesticides (Robeck et al., 1965) and pharmaceutical products (Garrison et al., 1976; Hignite and Azarnoff, 1977), and still at the present time, despite strict legislations.

In the European Union, two political decisions had a major effect in raising awareness about the quality of water bodies: firstly, the urban wastewater treatment directive in 1991 (European Commission, 1991b), and then, in 2000, the water framework directive (European Commission, 2000). These two texts aimed at improving the quality of water environments in Europe by targeting the collection and treatment of wastewater, and ensuring a good ecological status of 
water bodies in the future, respectively. These political decisions were accompanied by technical evolutions allowing the detection and quantification of numerous TrOCs in natural environments (Altenburger et al., 2015; Loos et al., 2009; McCance et al., 2018). However, depending on the TrOC targeted, the contamination of environmental compartments can be much older than the first detection, hindering the proper understanding of the historical contamination of water bodies.

In order to reconstruct the historical contamination of water bodies, sedimentary archives are considered as particularly relevant, especially concerning PAHs or PCBs (Ayrault et al., 2020; Dendievel et al., 2020; Santschi et al., 2001), which are hydrophobic and persistent organic contaminants. However, recent studies have demonstrated that more hydrophilic contaminants, such as pesticides (excluding organo-chlorine pesticides such as DDT) and pharmaceutical products, may also be recorded in sedimentary archives (Lahti and Oikari, 2012; Lara-Martín et al., 2015), showing the relevance of sedimentary archives to study the temporal record of TrOC deposition associated with particulate matter.

Yet, once the vertical distribution of contaminants has been obtained, interpreting the patterns may be challenging. Generally, most authors concur that the oldest detection of a specific contaminant is concurrent with or posterior to the market launch date of the investigated contaminant (Kerrigan et al., 2018; Klaminder et al., 2015), in view of their weak mobility within the sedimentary column and limited degradation due to adsorption onto solids (Keil et al., 1994). Another strong assumption is that the sedimentary occurrence of contaminants is related to their dissolved concentration and solid/water partition coefficient (Lara-Martín et al., 2015; Thiebault et al., 2017). However, unlike hydrophobic contaminants, for which the sedimentary occurrences are considered to be proportional to the historical environmental contamination through the organic content of sediment (Castro and Vale, 1995), for hydrophilic contaminants, variations in both watercourse conditions (da Silva et al., 2011; Zhou and 
Broodbank, 2014) or sedimentary compositions (Al-Khazrajy and Boxall, 2016; Kodešová et al., 2015; Stein et al., 2008) may impact the solid/water partition non-linearly. It is therefore important to assess the vertical variation of the sediment composition (granulometry, organic content) in order to avoid misunderstanding the observed pattern. Moreover, it is also mandatory to develop an appropriate age model to date such sedimentary archives in order to assess the temporal continuity of sediment deposition, and the potential presence of major disturbances or hiatuses along the core (Fuller et al., 1999; Vrel et al., 2013).

The vertical variation in the concentration of rather hydrophilic contaminants therefore depends on several factors, as already mentioned, (i) the adsorption potential of the sediment; (ii) the amount of contaminant used in the watershed; and finally, (iii) the impact of potential filters between the place of use and the watercourse. On the latter point, it is very important to have a proper evaluation of the main sources of the contaminants investigated. For example, it has been known for some time that most pharmaceutical products (except livestock production sources) are discharged into the environment through wastewater treatment plants (WWTP), in which their removal are incomplete (Verlicchi et al., 2012). However, both sewer networks and wastewater treatment technologies have considerably evolved in the last 60 years (De Feo et al., 2014; Hara et al., 2016). Pesticides discharged into the environment are more difficult to trace, as even though most pesticides are used in the field for crop protection, generating a diffuse source toward water bodies, a significant amount of pesticides is also rejected by point sources, such as wastewater and stormwater discharge points (Blanchoud et al., 2004; Botta et al., 2009; Zgheib et al., 2012).

Moreover, the vertical distribution of TrOCs such as pharmaceutical products and pesticides within sedimentary archives is the result of multiple factors and a careful investigation into the historical evolution of the watershed is needed. In this study, therefore, we investigated the occurrence of 41 TrOCs in a sedimentary archive located in a highly anthropized estuary (Seine 
estuary, downstream the cities of Rouen and Paris, France). The targeted TrOCs are pharmaceutical products and pesticides, both parent compounds and some major metabolites. From an analysis of their vertical distribution, the aim was (i) to investigate the use of TrOCs as chronomarkers; (ii) to access a long term chronology of TrOC contamination; and (iii) to evaluate the respective impact of the sedimentary composition, the WWTP evolution and the change in use in the watershed on TrOC sedimentary occurrences.

\section{Material and Methods}

\subsection{Site Settings}

The coring site is located in the upper estuary of the Seine River (Figure 1), in a disused dock at Rouen called “Darse des Docks”. Historical bathymetric charts and data provided by the Grand Port Maritime de Rouen (GPMR; Rouen harbor authority) allowed us to assume that the site chosen for the coring had remained undisturbed since 1960 (Kaci et al., 2014; Vrel et al., 2013). Sediments from the harbor basin were lying on semi-confined gravel and chalk aquifers that were connected to groundwater. The coring site is located in the Rouen agglomeration (110 000 inh. for the city and 660000 inh. for the entire urban area) and is situated downstream the discharge points of two major WWTPs, E and GQ, and upstream the discharge of GC effluents (Figure 1). The Seine river is also impacted upstream (i.e. > $100 \mathrm{~km}$ ) by the discharge of the effluent of SA, the largest WWTP in France.

This site was also selected as the Seine estuary is the outlet of contamination of the Seine watershed, where nearly $40 \%$ of the French population is concentrated, including the Paris megacity, 30\% of French industrial activity until recent decades and nearly $40 \%$ of national agricultural activity. It therefore appeared that this site should be particularly relevant for the analysis of the historical contamination by TrOCs of various classes. 


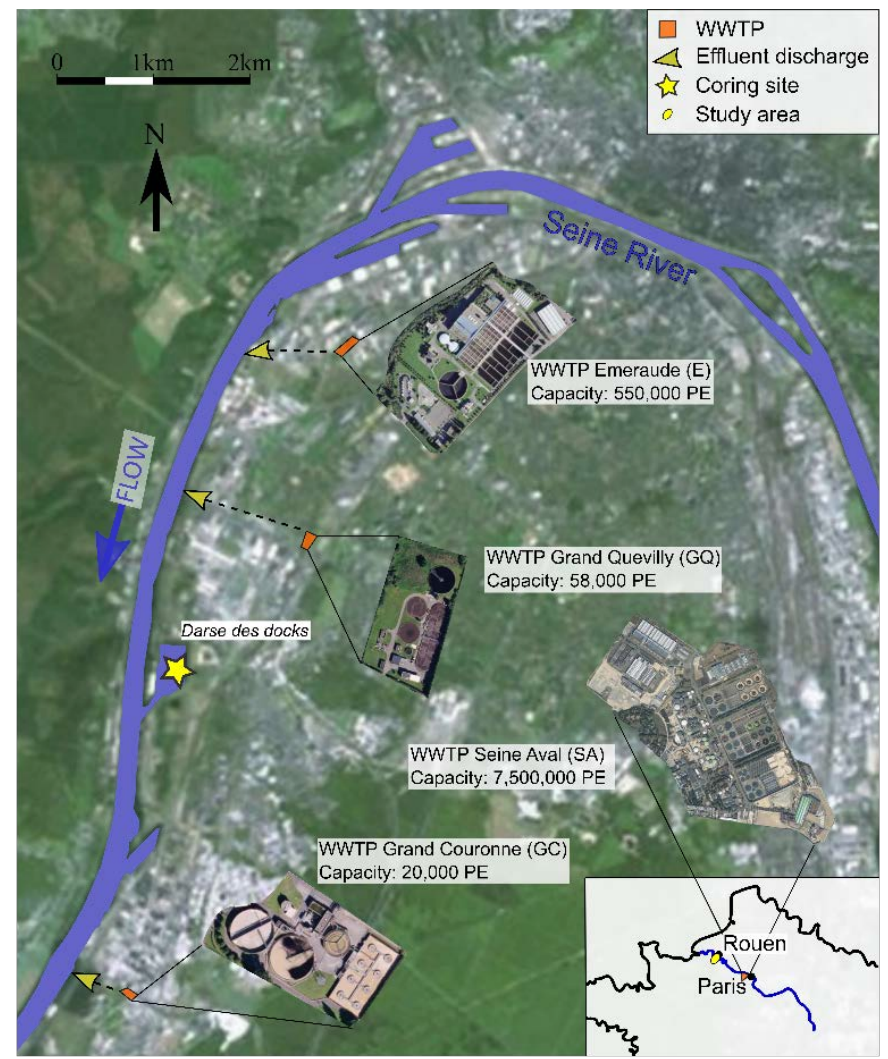

Figure 1: Aerial photograph (www.geoportail.gouv.fr) showing the coring site "Darse des docks" (yellow star) within the urban area of Rouen. Local wastewater effluent inputs into the Seine River and their current treatment capacities and technologies are highlighted (E, GQ, GC), and the upstream SA WWTP is also indicated. PE for Population-Equivalent.

\subsection{Sediment coring and sampling}

The core sampling was performed in 2010, using a percussion corer adapted for use on a barge, allowing the collection of a 580-cm core of consolidated mud. Then, a long box-corer (gravity corer) was also used to collect the superficial unconsolidated mud, thus making it possible to retrieve a 105-cm-long core which included the soft surface mud (not analyzed in this study, but useful for the age-modeling). Subsequently, the two cores were combined together into a single profile. The loss of sediment at the interface and the compaction induced by the percussion corer were corrected by assuming that no such sampling artefacts occurred using the gravity corer, and combining water content profiles (Vrel et al., 2013). Compaction was not estimated for deeper sediments. 
Immediately after the coring, the cores were aseptically cut in half lengthwise in a confined chamber. One half of each core was used for geochemical analyses and sediment dating, while the other half was subsampled into $5 \mathrm{~cm}$-thick sub-fractions using a sterile sub-corer and further placed in storage at $-80^{\circ} \mathrm{C}$ in less than an hour as previously described (Kaci et al., 2014).

\subsection{Sediment analysis and dating}

The particle size was determined by an enhanced laser diffraction particle size analyzer (Beckman Coulter, LS230). The total organic carbon (TOC) content of sediment samples was determined by elementary analysis after decarbonation of the bulk sediment with $\mathrm{HCl}(3 \mathrm{M})$. Fourier transform infrared (FTIR) measurements in the range $400-4000 \mathrm{~cm}^{-1}$, were recorded using a Bruker 55 FT-IR spectrometer equipped with an Nd:YAG laser operating at $1064 \mathrm{~nm}$ and a Ge detector. The analyses were performed in transmission mode and each spectrum was the average of 256 scans collected at $2 \mathrm{~cm}^{-1}$ resolution. About $0.01 \mathrm{~g}$ of material was mixed with $0.99 \mathrm{~g}$ of potassium bromide $(\mathrm{KBr})$ and pelletized with a hydraulic press at $10 \mathrm{kPa}$ during 5 minutes.

The analyses of artificial radionuclides $\left({ }^{137} \mathrm{Cs}\right.$ and plutonium isotopes) coupled with hydrological and bathymetric data made it possible to constrain a precise age-model, previously published (Vrel et al., 2013). This age-model allows the characterization of two sedimentary hiatuses along the profile, the first one between 1949 and 1960, and the second one between 1962 and 1965, explaining the lack of samples for these dates.

Hereafter, samples are labelled according to the date of the layer.

\subsection{Chemical reagents}

LC-MS grade acetonitrile (AcN) and methanol (MeOH) were purchased from VWR and ultrapure water $\left(\mathrm{H}_{2} \mathrm{O}\right)$ was prepared with a Pure Lab Chorus water purification system (Veolia Water). Formic acid (99\% purity) was purchased from Sigma-Aldrich. Isotopically labeled 
internal standards (ILIS) and reference standards were purchased from LGC Standards, assuming a purity $\geq 97 \%$. TrOCs were selected following the most frequently detected organic contaminants in European river waters (Loos et al., 2013).

\subsection{Enrichment and clean-up of sediment extracts}

Sediments were collected on cores following a regular sampling step $(5 \mathrm{~cm})$. After freezing at $-80^{\circ} \mathrm{C}$, they were then freeze-dried during $24 \mathrm{~h}$ before being crushed in a mortar, and $1 \pm 0.1 \mathrm{~g}$ was subsampled. Samples were then spiked with $100 \mathrm{ng}$ of each ILIS at $4^{\circ} \mathrm{C}$ overnight. Spiked samples were then extracted by pressurized liquid extraction, using ASE-350 (Thermo). The extraction mixture was $\mathrm{MeOH} / \mathrm{H}_{2} \mathrm{O}(1: 1 \mathrm{v} / \mathrm{v})$ and the operating temperature and pressure were $100^{\circ} \mathrm{C}$ and 1000 psi respectively. Extracts were then reduced to $1 \mathrm{~mL}$ using an EZ-2 evaporator (Biopharma Technologies), prior to refilling at $100 \mathrm{~mL}$ of $\mathrm{H}_{2} \mathrm{O}$ before purification by solidphase extraction (SPE) on Oasis-HLB columns (6 mL x $150 \mathrm{mg}$, Waters). Cartridges were conditioned with $5 \mathrm{~mL}$ of $\mathrm{MeOH}$ followed by $5 \mathrm{~mL}$ of ultra-pure water. Then, the cartridges were filled with the sample (100 mL) prior to flushing with 2 x $5 \mathrm{~mL}$ of ultra-pure water before drying for 30 minutes under vacuum. Finally, elution of TrOCs was performed with 2 x $5 \mathrm{~mL}$ of $\mathrm{MeOH}$ before drying under nitrogen flow and filtration at $0.22 \mu \mathrm{m}$. Extracts were finally recovered in $\mathrm{MeOH}$ before injection. The analytical and quantification procedure is further detailed in the supplementary data (Tables S1-S2).

Table 1: General properties of the targeted TrOCs, with Ab. the abbreviation, $\mathrm{M}_{\mathrm{w}}$ the molecular weight in g.mol ${ }^{-1}$, $\mathrm{Sol}_{\mathrm{w}}$ the water solubility at $25^{\circ} \mathrm{C}$ and $\mathrm{pH}=7$ in mg. $\mathrm{L}^{-1}$, Charge the charge state at $\mathrm{pH}=7$ and MAD the market authorization date, deriv. for derivatives, * indicates by-products. Data extracted from Chemspider Database

\begin{tabular}{|c|c|c|c|c|c|c|c|c|c|c|c|c|}
\hline Type & Chemical Group & Name & Ab. & Formula & CAS-Number & $\mathrm{M}_{\mathrm{w}}$ & $\mathrm{pK}_{\mathrm{a}}$ & $\log K_{o w}$ & $\log K_{o c}$ & Sol $_{w}$ & Charge & $\mathrm{MAD}^{\mathrm{a}, \mathrm{b}}$ \\
\hline \multicolumn{13}{|c|}{ Pharmaceutical Products } \\
\hline \multirow[t]{11}{*}{ Antibiotics } & $\beta$-Lactam & Amoxicillin & AMO & $\mathrm{C}_{16} \mathrm{H}_{19} \mathrm{~N}_{3} \mathrm{O}_{5} \mathrm{~S}$ & $26787-78-0$ & 365.40 & $3.2-7.4$ & 0.97 & 2.94 & 2,702 & $+/-$ & 1972 \\
\hline & Cycline & Tetracycline & TET & $\mathrm{C}_{22} \mathrm{H}_{24} \mathrm{~N}_{2} \mathrm{O}_{8}$ & $60-54-8$ & 444.43 & 8.2 & -1.33 & 1.76 & 231 & + & 1948 \\
\hline & Diaminopyrimidine & Trimethoprim & TMP & $\mathrm{C}_{14} \mathrm{H}_{18} \mathrm{~N}_{4} \mathrm{O}_{3}$ & $738-70-5$ & 290.32 & 7.2 & 0.73 & 2.96 & 400 & $0 /+$ & 1968 \\
\hline & \multirow[t]{4}{*}{ Fluoroquinolone } & Ciprofloxacin & CIP & $\mathrm{C}_{17} \mathrm{H}_{18} \mathrm{FN}_{3} \mathrm{O}_{3}$ & $85721-33-1$ & 331.34 & $5.8-8.7$ & 0.28 & 1.55 & 1,350 & $+/-$ & 1987 \\
\hline & & Enrofloxacin & ENR & $\mathrm{C}_{19} \mathrm{H}_{22} \mathrm{FN}_{3} \mathrm{O}_{3}$ & 93106-60-6 & 359.39 & $5.7-6.7$ & 0.70 & 1.92 & 612 & - & 1970's \\
\hline & & Norfloxacin & NOR & $\mathrm{C}_{16} \mathrm{H}_{18} \mathrm{FN}_{3} \mathrm{O}_{3}$ & $70458-96-7$ & 319.33 & $5.8-8.7$ & -0.31 & 1.96 & 280 & $+/-$ & 1985 \\
\hline & & Ofloxacin & OFL & $\mathrm{C}_{18} \mathrm{H}_{20} \mathrm{FN}_{3} \mathrm{O}_{4}$ & 82419-36-1 & 361.37 & $5.5-6.2$ & -2.00 & 1.65 & 4,000 & - & 1986 \\
\hline & Macrolide & Erythromycin & ERY & $\mathrm{C}_{37} \mathrm{H}_{67} \mathrm{NO}_{13}$ & $114-07-8$ & 733.93 & $8.4-12.4$ & 3.06 & 1.00 & 4.2 & + & 1952 \\
\hline & \multirow[t]{2}{*}{ Quinolone } & Flumequine & FLQ & $\mathrm{C}_{14} \mathrm{H}_{12} \mathrm{FNO}_{3}$ & $42835-25-6$ & 261.25 & 6.0 & 2.60 & 1.85 & 308 & - & 1976 \\
\hline & & Oxolinic Acid & $\mathrm{OXO}$ & $\mathrm{C}_{13} \mathrm{H}_{11} \mathrm{NO}_{5}$ & $14698-29-4$ & 261.23 & 5.6 & 1.70 & 1.00 & 3.2 & - & 1974 \\
\hline & Sulfonamide & Sulfamethoxazole & SMX & $\mathrm{C}_{10} \mathrm{H}_{11} \mathrm{~N}_{3} \mathrm{O}_{3} \mathrm{~S}$ & $723-46-6$ & 253.28 & $2.0-6.2$ & 0.89 & 3.19 & 610 & - & 1968 \\
\hline \multirow[t]{3}{*}{ Analgesics } & Acetylaniline & Acetaminophen & ACM & $\mathrm{C}_{8} \mathrm{H}_{9} \mathrm{NO}_{2}$ & $103-90-2$ & 151.16 & 9.6 & 0.46 & 1.79 & 14,000 & 0 & 1957 \\
\hline & Opioids & Codeine & COD & $\mathrm{C}_{18} \mathrm{H}_{21} \mathrm{NO}_{3}$ & $76-57-3$ & 299.36 & 8.2 & 1.28 & 3.12 & 577 & + & $1840 \mathrm{~s}$ \\
\hline & & Tramadol & TRA & $\mathrm{C}_{16} \mathrm{H}_{25} \mathrm{NO}_{2}$ & $27203-92-5$ & 263.37 & 9.4 & 3.01 & 2.91 & 1,151 & + & 1997 \\
\hline Anticonvulsants & Dibenzazepine & Carbamazepine & CBZ & $\mathrm{C}_{15} \mathrm{H}_{12} \mathrm{~N}_{2} \mathrm{O}$ & $298-46-4$ & 236.27 & 13.9 & 2.45 & 3.56 & 18 & 0 & 1974 \\
\hline$\beta$-blockers & Ethanolamine & Atenolol & ATE & $\mathrm{C}_{14} \mathrm{H}_{22} \mathrm{~N}_{2} \mathrm{O}_{3}$ & $29122-68-7$ & 266.34 & 9.6 & 0.16 & 2.17 & 13,300 & + & 1978 \\
\hline
\end{tabular}




\begin{tabular}{|c|c|c|c|c|c|c|c|c|c|c|c|c|}
\hline & & Propranolol & PRP & $\mathrm{C}_{16} \mathrm{H}_{21} \mathrm{NO}_{2}$ & $525-66-6$ & 259.34 & 9.7 & 2.60 & 3.09 & 61.7 & + & 1965 \\
\hline Hypolipidemic & Fibrate & Bezafibrate & BZB & $\mathrm{C}_{16} \mathrm{H}_{20} \mathrm{ClNO}_{4}$ & $41859-67-0$ & 361.82 & 3.87 & 4.25 & 3.17 & 1.55 & - & 1982 \\
\hline \multirow{2}{*}{$\begin{array}{l}\text { Non-Steroidial } \\
\text { Anti-Inflamm. }\end{array}$} & Acetic acid deriv. & Diclofenac & DCF & $\mathrm{C}_{14} \mathrm{H}_{11} \mathrm{Cl}_{2} \mathrm{NO}_{2}$ & $15307-79-6$ & 296.15 & 4.2 & 4.02 & 2.92 & 2.37 & - & 1950 's \\
\hline & Propionic acid deriv. & Ketoprofen & KET & $\mathrm{C}_{16} \mathrm{H}_{14} \mathrm{O}_{3}$ & 22071-15-4 & 254.28 & 4.5 & 3.00 & 2.46 & 51 & - & 1970 s \\
\hline \multirow{4}{*}{$\begin{array}{l}\text { Psychotropic } \\
\text { drugs }\end{array}$} & \multirow[t]{2}{*}{ Benzodiazepine } & Diazepam & DIA & $\mathrm{C}_{16} \mathrm{H}_{13} \mathrm{ClN}_{2} \mathrm{O}$ & $439-14-5$ & 284.74 & 3.4 & 2.70 & 4.05 & 50 & 0 & 1963 \\
\hline & & Oxazepam & OXA & $\mathrm{C}_{15} \mathrm{H}_{11} \mathrm{ClN}_{2} \mathrm{O}_{2}$ & $604-75-1$ & 286.71 & $1.7-11.6$ & 3.34 & 3.08 & 150 & 0 & 1965 \\
\hline & Diphenydramine deriv. & Fluoxetine & FLX & $\mathrm{C}_{17} \mathrm{H}_{18} \mathrm{~F}_{3} \mathrm{NO}$ & $54910-89-3$ & 309.33 & 9.8 & 4.65 & 5.32 & 1.7 & + & 1989 \\
\hline & Phenetylamine deriv. & Venlafaxine & VEN & $\mathrm{C}_{17} \mathrm{H}_{27} \mathrm{NO}_{2}$ & $93413-69-5$ & 277.40 & 8.9 & 3.28 & 3.17 & 267 & + & 1993 \\
\hline \multicolumn{13}{|l|}{ Pesticides } \\
\hline \multirow[t]{2}{*}{ Fungicide } & Benzimidazole & Carbendazim & CBD & $\mathrm{C}_{9} \mathrm{H}_{9} \mathrm{~N}_{3} \mathrm{O}_{2}$ & 10605-21-7 & 191.19 & 4.5 & 1.55 & 2.24 & 8 & 0 & 1967 \\
\hline & Triazole & Tebuconazole & TEB & $\mathrm{C}_{16} \mathrm{H}_{22} \mathrm{ClN}_{3} \mathrm{O}$ & $107534-96-3$ & 307.82 & 5.0 & 3.89 & 4.32 & 36 & 0 & 1986 \\
\hline Biocide & Triazine & Irgarol & IRG & $\mathrm{C}_{11} \mathrm{H}_{19} \mathrm{~N}_{5} \mathrm{~S}$ & $28159-98-0$ & 253.37 & 4.1 & 4.07 & 2.38 & 7.52 & 0 & - \\
\hline \multirow[t]{14}{*}{ Herbicide } & \multirow[t]{2}{*}{ Organochlorine } & Metazachlor & MTZ & $\mathrm{C}_{14} \mathrm{H}_{16} \mathrm{ClN}_{3} \mathrm{O}$ & 67129-08-2 & 277.75 & - & 2.38 & 2.80 & 430 & 0 & 1983 \\
\hline & & Metolachlor & MTC & $\mathrm{C}_{15} \mathrm{H}_{22} \mathrm{ClNO}_{2}$ & $51218-45-2$ & 283.79 & - & 3.24 & 2.47 & 530 & 0 & 1975 \\
\hline & Oxadiazole & Oxadiazon & OXD & $\mathrm{C}_{15} \mathrm{H}_{18} \mathrm{Cl}_{2} \mathrm{~N}_{2} \mathrm{O}_{3}$ & $19666-30-9$ & 345.22 & 2.7 & 4.81 & 3.54 & 0.7 & - & 1969 \\
\hline & Phenoxynicotinanilide & Diflufenican & DFF & $\mathrm{C}_{19} \mathrm{H}_{11} \mathrm{~F}_{5} \mathrm{~N}_{2} \mathrm{O}_{2}$ & $83164-33-4$ & 394.30 & - & 3.53 & 5.04 & 0.05 & 0 & 1988 \\
\hline & \multirow[t]{3}{*}{ Phenylurea } & 3,4 Dichloroaniline* & DCA & $\mathrm{C}_{6} \mathrm{H}_{5} \mathrm{Cl}_{2} \mathrm{~N}$ & $95-76-1$ & 162.02 & 3.0 & 2.37 & 2.08 & 92 & 0 & - \\
\hline & & Chlortoluron & CHT & $\mathrm{C}_{10} \mathrm{H}_{13} \mathrm{ClN}_{2} \mathrm{O}$ & $15545-48-9$ & 212.67 & 14.0 & 2.58 & 2.13 & 70 & 0 & 1970 \\
\hline & & Isoproturon & ISO & $\mathrm{C}_{12} \mathrm{H}_{18} \mathrm{~N}_{2} \mathrm{O}$ & $34123-59-6$ & 206.28 & 0.1 & 2.84 & 2.40 & 70 & 0 & 1974 \\
\hline & \multirow[t]{2}{*}{ Sulfonylurea } & Nicosulfuron & NIC & $\mathrm{C}_{15} \mathrm{H}_{18} \mathrm{~N}_{6} \mathrm{O}_{6} \mathrm{~S}$ & 111991-09-4 & 410.41 & 4.3 & -1.15 & 1.33 & 1,200 & - & 1993 \\
\hline & & Prosulfuron & PRS & $\mathrm{C}_{15} \mathrm{H}_{16} \mathrm{~F}_{3} \mathrm{~N}_{5} \mathrm{O}_{4} \mathrm{~S}$ & $94125-34-5$ & 419.38 & 3.8 & 3.56 & 3.54 & 4,000 & - & 1999 \\
\hline & \multirow[t]{5}{*}{ Triazine \& deriv. } & Atrazine & ATZ & $\mathrm{C}_{8} \mathrm{H}_{14} \mathrm{ClN}_{5}$ & $1912-24-9$ & 215.68 & 1.7 & 2.82 & 2.36 & 33 & 0 & 1959 \\
\hline & & Desethylatrazine* & DEA & $\mathrm{C}_{6} \mathrm{H}_{10} \mathrm{ClN}_{5}$ & $6190-65-4$ & 187.63 & 1.4 & 1.78 & 1.94 & 3,200 & 0 & - \\
\hline & & Deisopropylatrazine* & DIA & $\mathrm{C}_{5} \mathrm{H}_{8} \mathrm{ClN}_{5}$ & $1007-28-9$ & 173.60 & 1.5 & 1.36 & 1.75 & 670 & 0 & - \\
\hline & & Hydroxyatrazine* & HTZ & $\mathrm{C}_{8} \mathrm{H}_{15} \mathrm{~N}_{5} \mathrm{O}$ & $2163-68-0$ & 197.24 & 4.6 & 2.09 & 2.25 & 5.9 & 0 & - \\
\hline & & Simazine & SIM & $\mathrm{C}_{7} \mathrm{H}_{12} \mathrm{ClN}_{5}$ & $122-34-9$ & 201.66 & 1.6 & 2.40 & 2.17 & 6.2 & 0 & 1957 \\
\hline
\end{tabular}

184

References: ${ }^{a}$ Chast, (2012); ${ }^{b}$ Chauvel et al., 2012)

\subsection{Quantification procedure}

TrOC separation was achieved at $40^{\circ} \mathrm{C}$ with a Zorbax Eclipse Plus C18 chromatographic column (2.1 mm x 150 mm x 3.5 $\mu \mathrm{m}$; Agilent) using a 1200 SL HPLC system (Agilent). The injection volume was $10 \mu \mathrm{L}$ and the flow rate $0.3 \mathrm{~mL} \cdot \mathrm{min}^{-1}$. Two solvents were used as mobile phase; AcN (solvent A) and Milli-Q water (solvent B) both acidified with $0.1 \%$ of formic acid. The elution gradient was a transition from $95 \%$ to $0 \%$ of B in 9.5 min followed by 4 min of $100 \%$ of $\mathrm{A}$ and then a return to the initial conditions (95\% of B) during 3.5 min for a total analysis time of $18.5 \mathrm{~min}$. The chromatography system was coupled to a 6410B triple quadrupole mass spectrometer (Agilent) equipped with a heated electrospray ionization (HESI) interface operating in positive mode and at a flow rate of $0.3 \mathrm{~mL} \cdot \mathrm{min}^{-1}$. The multiple reaction monitoring (MRM) transitions and further details on the detection and quantification procedures are given in the supplementary data (Tables S1-S2). During each analytical run, blanks and quantification controls were regularly used in order to crosscheck the quantification quality.

\subsection{Validation}

The limits of quantification (LOQ) and limits of detection (LOD) of the method were calculated using the signal-to-noise (S/N) ratios (Table S3). LOD and LOQ were determined by extracting 
spiked (100 ng.g $\left.{ }^{-1}\right)$ matrix-matched $(n=5)$ sediment samples. Then, LOD and LOQ were respectively calculated based on a ratio between spiked amount and $\mathrm{S} / \mathrm{N}$ ratios multiplied by 3 and 10 for LOD and LOQ respectively. The recovery ratios were also evaluated in these experiments (spiking concentration $=100 \mathrm{ng} \cdot \mathrm{g}^{-1}, \mathrm{n}=5$ ), using the same extraction and quantification protocol as for the samples.

\section{Results}

\subsection{Sedimentary composition}

The qualitative composition of the samples according to their deposition date was evaluated using FTIR analyses (Figure S1). The main bands are associated with the main components of the sediments; i.e. carbonates, silicates and organic matter (Tinti et al., 2015). The relative proportion of each is not the point here, although it is worth noting that no significant variations in the spectra were visible for the samples selected. This means that no sudden variations occurred in the whole sedimentary composition, at least using this qualitative analysis, confirming a relatively homogeneous organo-mineral composition along the sedimentary profile.

The grainsize distributions of the sampled sediments are presented in Figure 2. All along the vertical profile, the grainsize is dominated by silts which are almost steady around $70 \%$. Conversely, the relative proportion of sands overall increased from a mean value of $12 \%$ between 1945 and 1980 to a mean value of $21 \%$ in the most recent layers. The opposite pattern is visible for clay grainsize, for which the relative proportion decreased from $17 \%$ between 1945 and 1980 to a mean value of 9\% since 1980. 


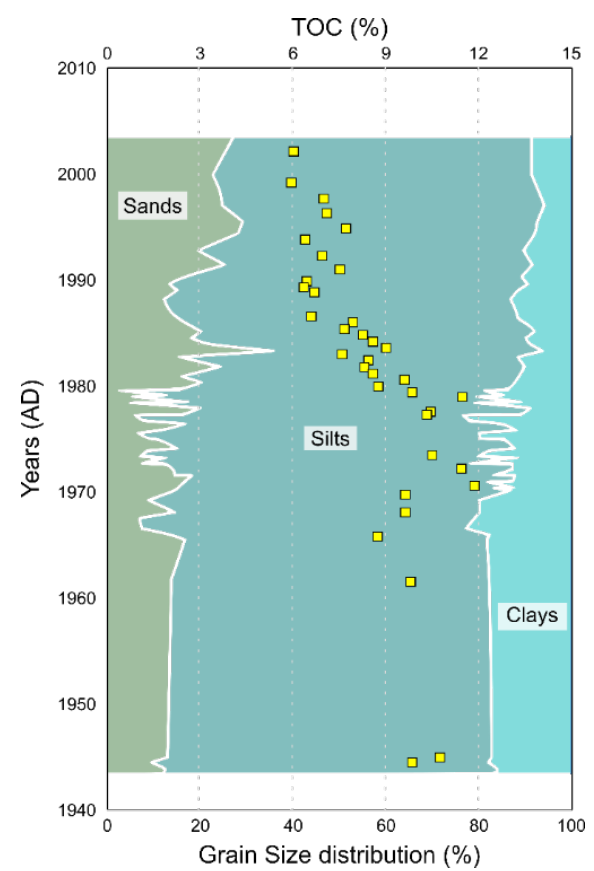

Figure 2: Total organic carbon (yellow squares, in \%) and grain size distribution in three major fractions in \% (clays in light green, silts in green and sands in light brown) of the sampled sediments

The change in TOC values along the core seems to be closely connected with the grainsize variations, as TOC is almost steady between 1945 and 1980 with a mean value of 10\%, followed by a decrease in the TOC value between 1980 and 1990, and since then, an almost constant TOC value around $6.5 \%$.

These similar temporal fluctuations of clay grainsize and TOC are significantly correlated $(p<$ 0.001), and even if the TOC content does not exclusively depend on the clay proportion (i.e. $\mathrm{R}^{2}$ $=0.41$ ), the higher surface area of the finest grainsize fractions plays an important role in the organic carbon storage.

\subsection{Occurrences of TrOCs in sediments}

Among the 41 targeted TrOCs, 23 were quantified at least once. Most of the concentrations ranged between 1 and 10 ng.g ${ }^{-1}$ except for COD and several antibiotics. The maximum concentrations were 256 and 550 ng.g $^{-1}$ for COD and TET, respectively. Whatever the TrOC, the vertical distribution was characterized by a first occurrence, at different depths depending on the molecule, followed by an almost continuous detection until the most recent sedimentary 
layers. Two main patterns were displayed: (i) an increase in the concentrations followed by a

241 decrease in the most recent sediments (e.g. FLQ and TET, Figure 3); and (ii) a continuous 242 increase in the concentrations since the first detection (e.g. TRA, Figure 4 and CBD, Figure 5).

243 It is noteworthy that for the TrOCs investigated, the market authorization date was

244 systematically older than their first detection. In this archive, other authors have indicated the

245 possible connection with groundwaters (Kaci et al., 2016), which is not confirmed here as the

246 oldest sampled layers (respectively dating from 1944.5 and 1945) were deprived of any TrOC

247 contamination (Figures 3, 4 and 5). For clarity, the vertical distribution of TrOC will be

248 hereafter discussed within three main groups, antibiotics, pharmaceutical products and 249 pesticides.

250

251

252

253

254

255

256

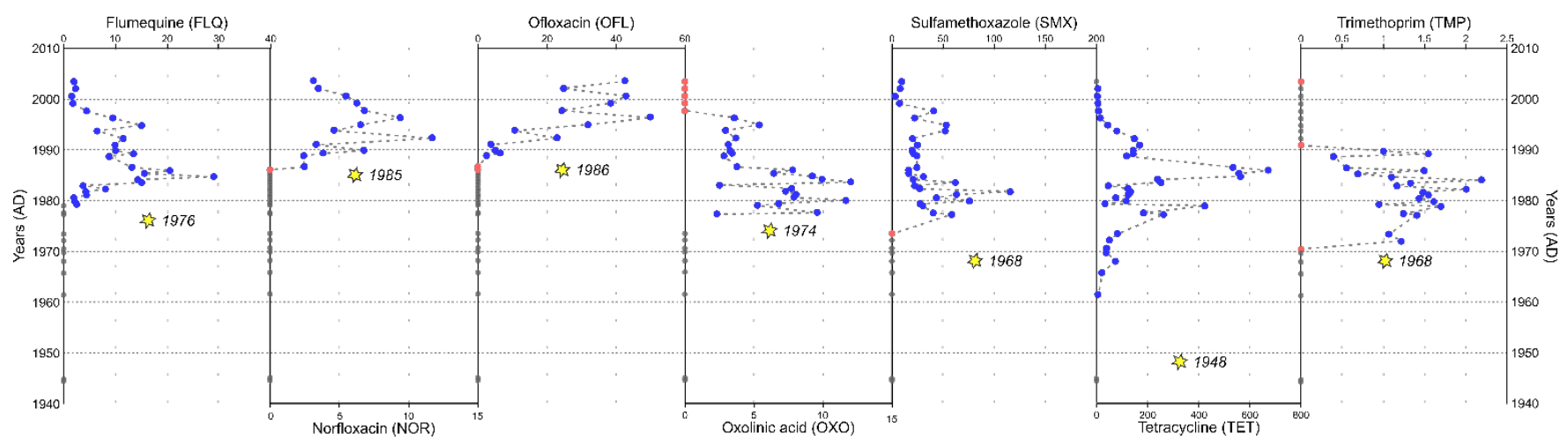

Figure 3: Distribution of antibiotics along the sedimentary profile by year. Concentrations are expressed in ng $\mathrm{g}^{-1}$ of dried sediment. Grey squares indicate concentrations below LOD, whereas red squares indicate concentrations below LOQ. The yellow star refers to the market authorization date (MAD, Table 1).

\subsubsection{Antibiotics}

Among 11 targeted antibiotics, 7 were quantified and displayed in general an increase in concentration followed by a decrease in the most recent sedimentary layers (Figure 3). The maximum concentrations were reached between 1980 and 1985 for FLQ, OXO, SUL, TET and TMP, whereas the maximum concentrations of NOR and OFL were more recent, i.e. between 1991 and 1997 due to their later market authorization date. A significant decrease in the concentrations of all the compounds can be observed in the latest layers, especially since 1990 for TMP, since 1992 for TET and since 1997 for the other antibiotics. This decrease is 
particularly noticeable on OXO which has been <LOQ since 1998 and TMP, which has been mostly $<$ LOD since 1990 .

\subsubsection{Other Pharmaceuticals}

265

266

Within this group, 7 compounds were detected amongst 13 (Figure 4). The MADs of these TrOCs range from 1842 for COD, to 1997 for TRA. COD displays an atypical pattern with several occurrences between 1968 and 1980 with a very high concentration (i.e. 256 ng.g ( $^{-1}$ ) in 1973 whereas this molecule was not detected in the other samples.

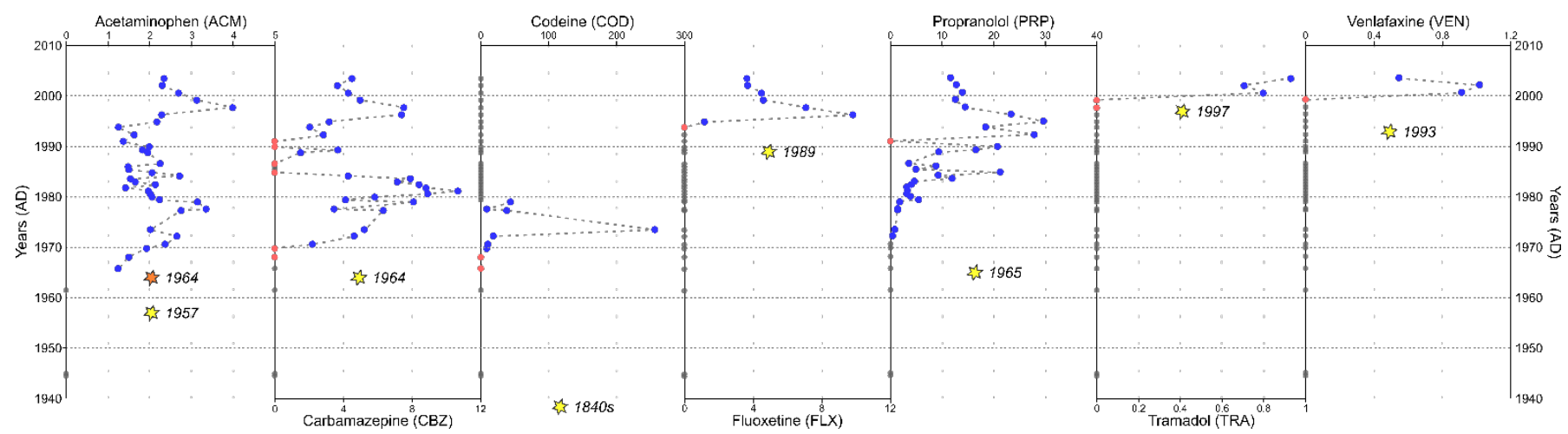

Figure 4: Distribution of PPs (other than ATBs) along the sedimentary profile by year. Concentrations are expressed in $\mathrm{ng} \mathrm{g}^{-1}$ of dried sediment. Grey squares indicate concentrations below LOD, whereas red squares indicate concentrations below LOQ. The yellow star refers to the market authorization date (MAD, Table 1), whereas the orange star refers to another MAD event.

FLX, VEN and TRA were the most recently marketed pharmaceuticals, respectively in 1989, 1993 and 1997. Whereas for VEN and TRA only 3 quantifications were made, in the three latest sedimentary layers, FLX displayed an increase in concentration until 1997, followed by a regular decrease in concentration. The same pattern (i.e. global increase until the late 1990s) is visible for PRP, despite an older MAD. ACM was initially launched for pediatric use only, before an extension to the entire population in 1964. Its pattern displays a first increase in concentration between 1965 and 1979, followed by a steady profile between 1980 and 1992, a second increase between 1993 and 1998, and a final decrease.

\subsubsection{Pesticides}


Among the 16 pesticides and derivatives investigated, 9 were detected (Figure 5). The highest concentrations were observed for CBD, DCA and DFF with several tens of ng.g ${ }^{-1}$. DCA and DFF displayed limited recovery ratios respectively due to a significant volatility (Crossland, 1990; Gatidou et al., 2004) and a high affinity with solids (Table 1).

The MAD of the detected pesticides ranged between 1951 for diuron (which with propanil and linuron launched in 1960 and 1965, and other biocides or industrial products, are the potential parent compounds of DCA) and 1988 for DFF. As observed for other TrOCs, no detection occurred before the MAD. The historical distribution of pesticides followed two types of patterns: (i) an almost constant increase in concentration, as for ISO and CBD, and (ii) an more pronounced in the most recent layers.

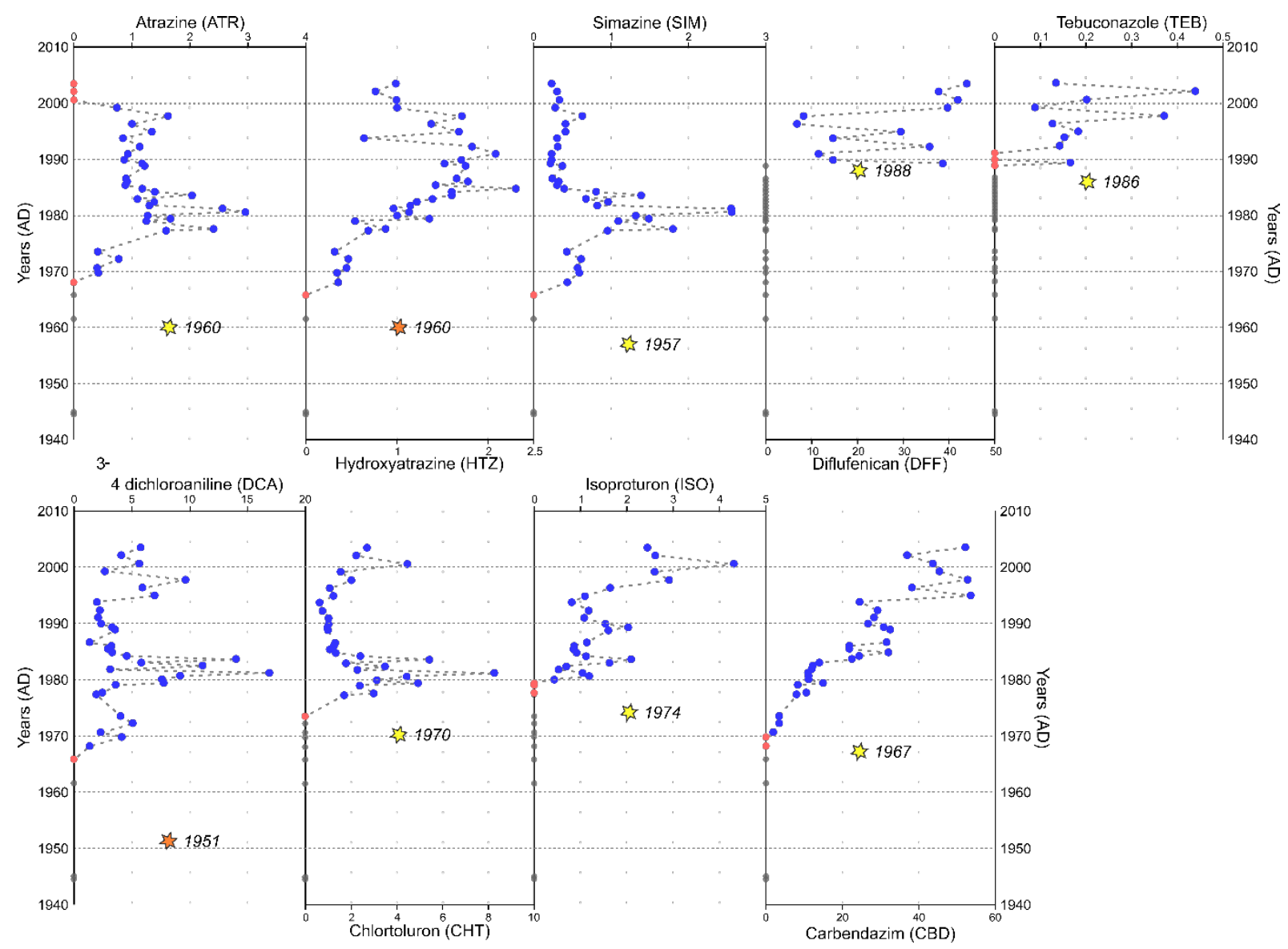

Figure 5: Distribution of pesticides along sedimentary profile by year. Concentrations are expressed in $\mathrm{ng} \mathrm{g}^{-1}$ of dried sediment. Grey squares indicate concentrations below LOD, whereas red squares indicate concentrations 
below LOQ. The yellow star refers to the market authorization date (MAD, Table 1), whereas the orange star refers to other MAD events (e.g. by-products).

\subsection{WWTP technology evolution}

301

WWTP effluents can be considered as the main environmental source of pharmaceuticals (Tran et al., 2019), and depending on the sewage network (i.e. separative or unitary), a significant amount of pesticides may also be present (Paijens et al., 2021). Located in an urban area, the coring site is impacted by the effluent discharge of the main WWTP of the Rouen conurbation, $3.5 \mathrm{~km}$ upstream, with a treatment capacity of 550,000 PE. Two minor effluent discharges, 2 $\mathrm{km}$ upstream and $6 \mathrm{~km}$ downstream (indicated here due to the tide effect), QG and GC respectively, also impacted the coring site. Finally, the effluents of the largest French WWTP, SA, located downstream Paris with a maximum treatment capacity of almost 7,500,000 PE in normal conditions are discharged into the Seine River more than $100 \mathrm{~km}$ upstream.

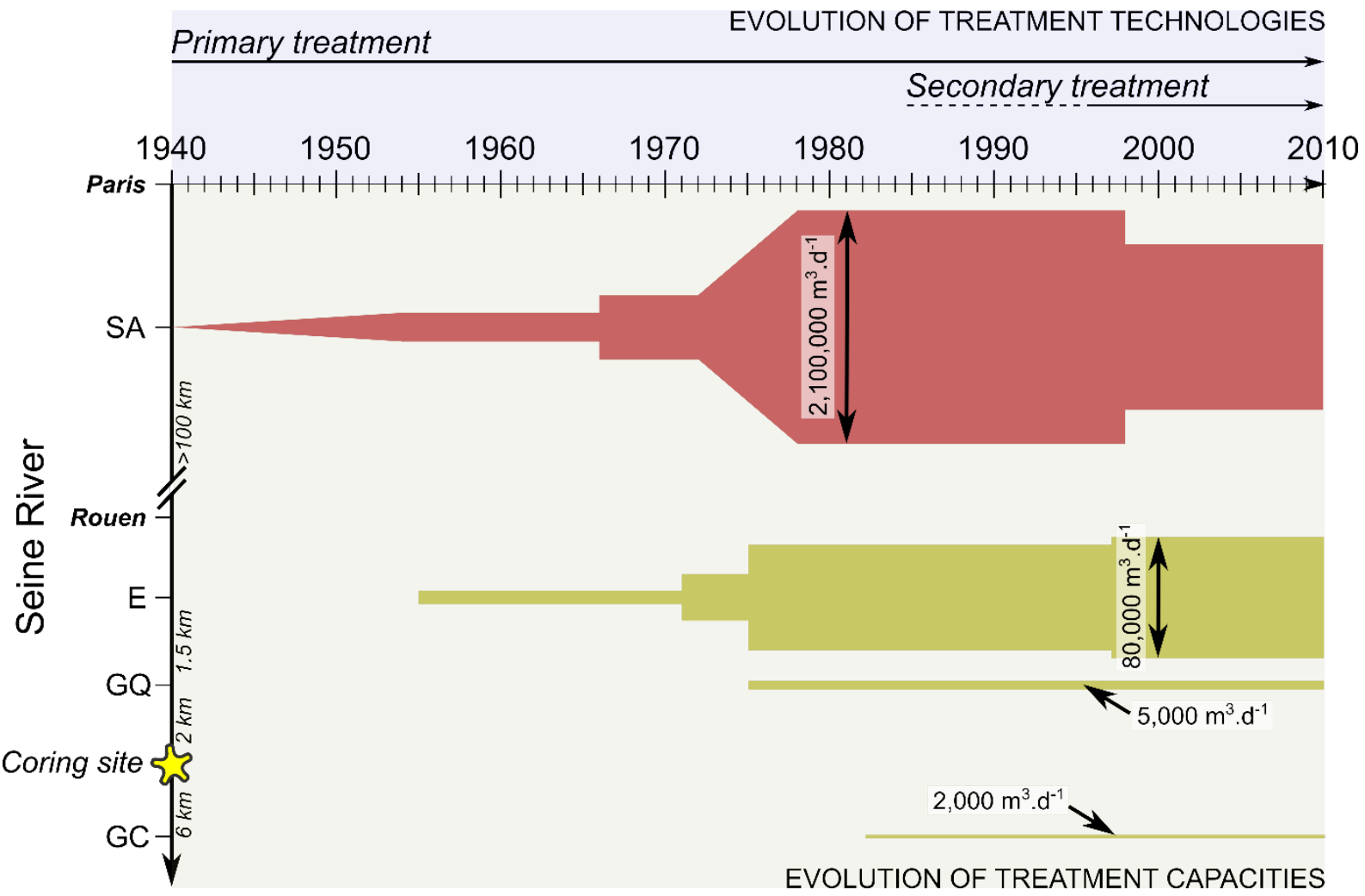

Figure 6: Temporal evolution of the main WWTPs (both treatment capacities and technologies) impacting the coring site (yellow star) along the Seine River. Data from Rocher et al. (2017) for SA and from Rouen sanitation service (personal communication) for E, GC and GQ. 
The evolution of the treatment technology used in these WWTPs primarily focused on improving the removal of classical parameters such as $\mathrm{BOD}_{5}, \mathrm{~N}$ (mostly organic) or suspended solids. As shown in Figure 6, for SA and E, there was a progressive increase in the treatment capacity following the increase in urbanization and the decline in agricultural spreading of wastewaters. This increase in the treatment capacity was accompanied by an evolution of the treatment technology, especially since the mid-1990s. For example, between 1954 and 1997 the E treatment chain was only a physico-chemical treatment with a focus on suspended solids and carbonaceous load, whereas since then a biological treatment, allowing a correct removal of $\mathrm{N}$ and P loads, was implemented.

It is difficult to gain precise historical knowledge of the feeding water in a sewage network. From the oldest available information (i.e. 2017) almost one third of the sewage network of the Rouen agglomeration is unitary, whereas two thirds are separative. However, it is most likely that these relative proportions have varied since 1945. Specifically, the unitary network might have been predominant during a long, but unknown, period of time.

\section{Discussion}

\subsection{A 50 years overview?}

Several authors have assumed that the vertical distribution of TrOCs within sedimentary archives may be connected with their historical occurrences in the dissolved phase, and thus their use in the watershed (Chiaia-Hernández et al., 2020). Considering this assumption, an increasing impact of two factors are expected since 1945: (i) the number of TrOCs detected should increase, in view of the exponential increase in the number of TrOCs marketed since this date, and (ii) the global concentration of TrOCs should also increase extensively as a result of the increase in the use of TrOCs. Of these two assumptions, the first one is verified in the sampled archive (Figure 7), with only one TrOC (i.e. TET) detected in the level 1961.5 and 21 
since the level 1999.2. This increase is consistent with the market authorization dates of the

339 targeted TrOCs, which are distributed all along the last 50 years. Consequently, it can be

340 assumed that sediments reflect the diversity of TrOC contamination well, at least for the most

341 persistent or the most concentrated of them. However, the comparison between the sedimentary

342 occurrences of TrOCs and their historical use in the watershed is not so obvious. First of all,

343 the historical use of pharmaceuticals and pesticides is not available at such a time scale (e.g.

344 records of the amounts of antibiotics sold in France began in 1999, Fig S3), and while it can be

345 considered that there has been an overall increase in the use of TrOCs in general since 1945,

346 this does not take into account the historical variation for one product, which can be more complex (i.e. banning, substitution, competition).

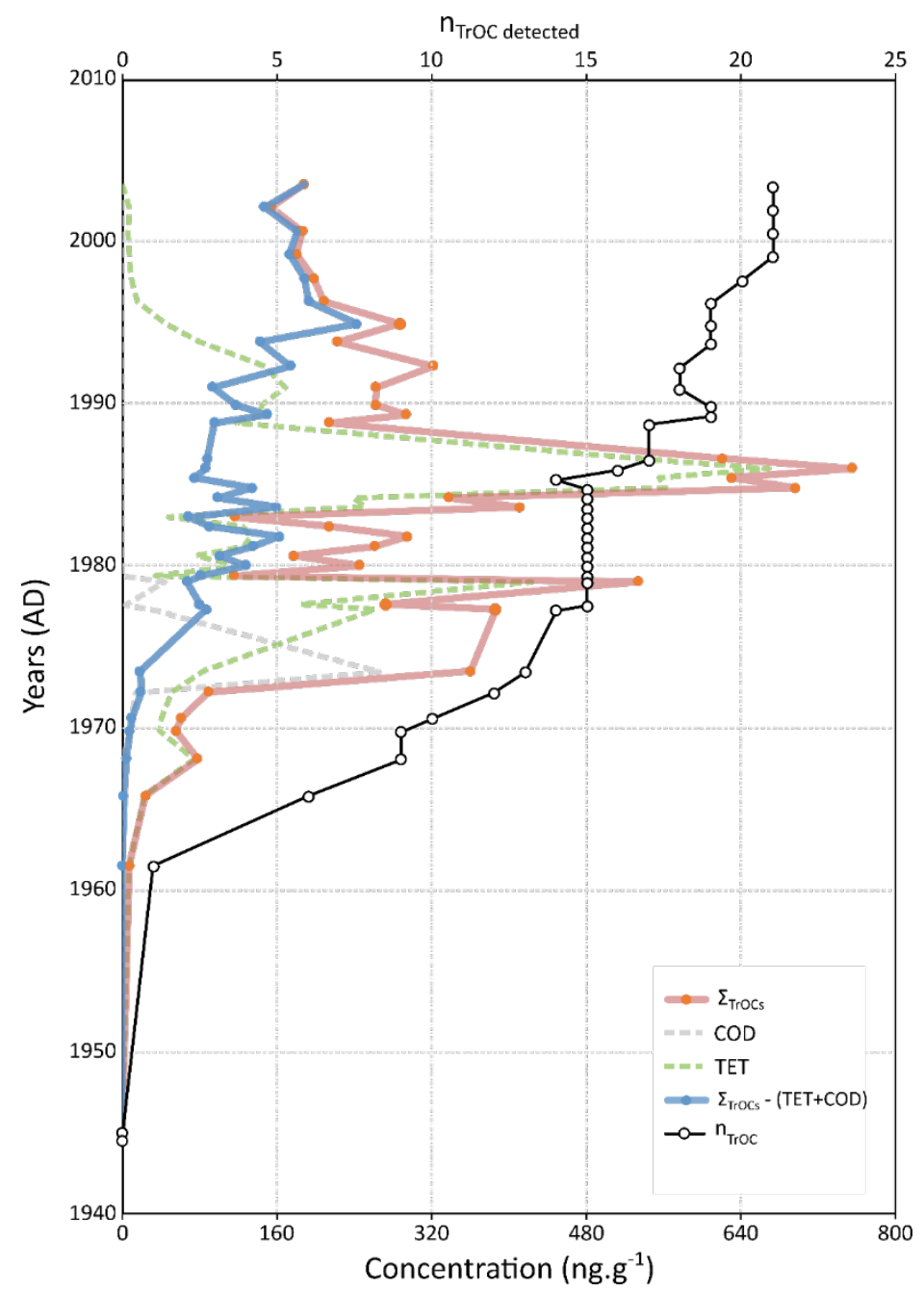


Figure 7: Total TrOC concentration (red line, $\Sigma_{\text {TrOCs }}$ ), Total TrOC concentration without COD and TET (blue line $\Sigma_{\text {TrOCs }}-($ TET $+C O D)$ ) and number of detected individual TrOCs (black line, $\mathrm{n}_{\text {TrOC }}$ ) along the core. COD (grey dotted line) and TET (green dotted line) distribution.

Looking at the sum of all TrOC occurrences, the layers with the highest concentrations dated from the late 1970s and middle 1980s (Figure 7). Yet, this pattern is heavily influenced by two TrOCs, TET and COD respectively (Figure S2), which can represent up to $88 \%$ of the total TrOC concentration for specific layers. Removing the concentrations of these two TrOCs, the total concentration reveals a progressive increase since the first occurrences in the middle 1960s. The concentrations of TET and COD are so much higher than the concentrations of other TrOCs that it directly affects the hierarchical cluster distribution of each sample when using raw concentration data (Figure S2). Indeed, each cluster only reflects the relative occurrence of TET or COD, and to a minor extent, SMX.

As a result, a second hierarchical cluster analysis was carried out on normalized concentrations between 0 and 1 for each TrOC ( 0 for $<$ LOD and 1 for the highest concentration, Figure 8 ). Two main TrOC clusters emerged from this analysis, mostly impacted by the market authorization dates on the one hand and by the historical increase in the sedimentary occurrences on the other hand. From this point of view, cluster A mostly accounts for TrOCs that exhibited their highest concentrations in the 1970s and the 1980s whereas cluster B mostly accounts for TrOCs that have exhibited their highest concentrations since 1990s. The sediment samples are also grouped in four distinct clusters that appear to be affected by TrOC diversity in sediments. There is a cluster for the oldest samples, containing the lowest diversity of TrOCs (<1979), another for the most recent samples (since 1989) and two other clusters in the 1980s impacted by the relative contribution of each TrOC cluster. This approach confirms that the 1980s were a period of significant modifications in the diversity and relative occurrence of TrOCs in this core that need to be addressed. 


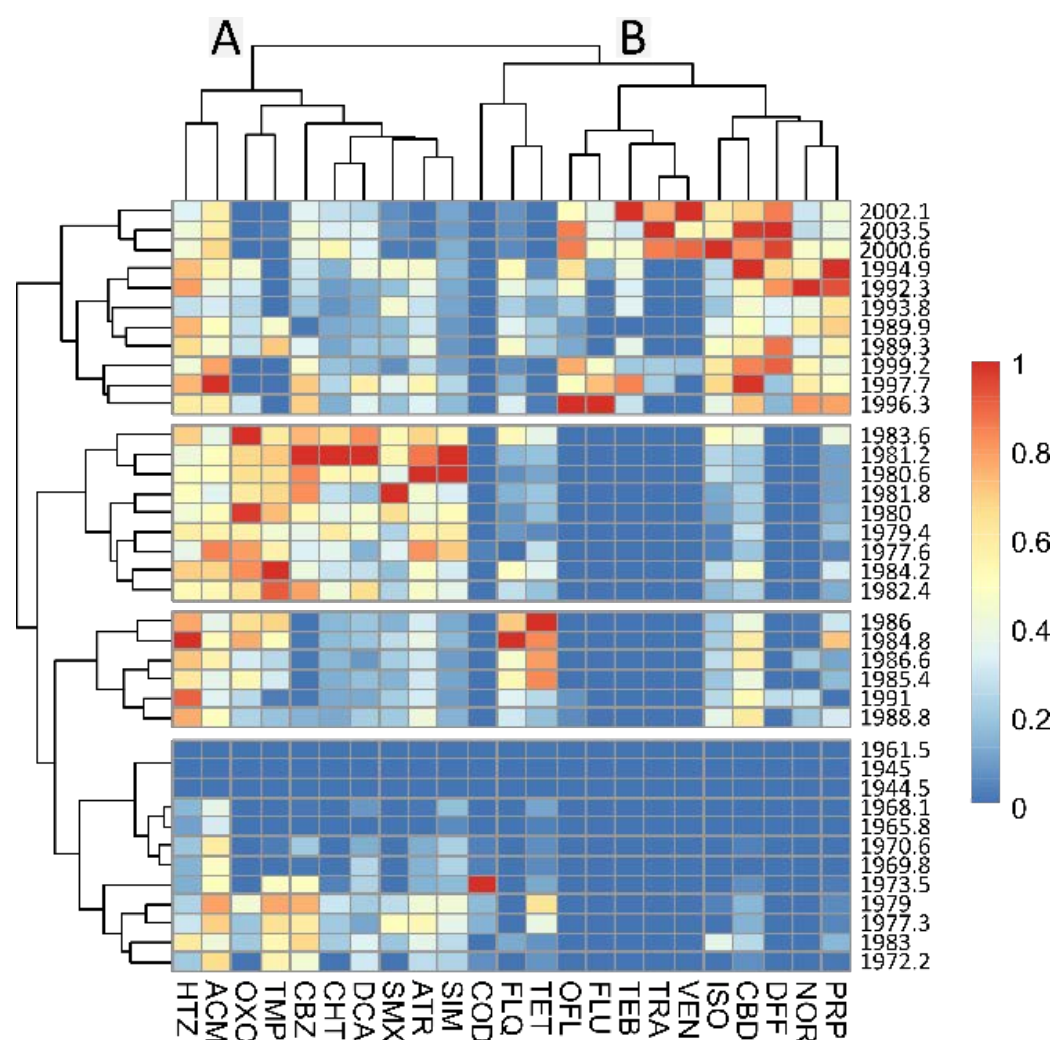

Figure 8: Heatmap analysis between the normalized occurrence of TrOCs and each analyzed layer by using R software (pheatmap package). The distance matrix was based on the Euclidian distance.

\subsection{Atypical patterns}

Several TrOCs displayed an atypical vertical distribution, considering that a typical pattern is an expected one and comparable between TrOCs. While in general we can observe an overall increase between the MAD and the late 1990s, this pattern is not visible for several TrOCs. For example, TMP has mostly been consumed in association with SMX since their common MAD in 1968 (Salter, 1982; Thiebault, 2020). However, although SMX, a persistent molecule often detected in the environment, was continuously detected since its first detection in 1973, TMP concentrations have been below LOQ or LOD since 1990. Yet, TMP was briefly sold alone on the French market between 1983 and 1990, the date at which TMP alone was withdrawn (Caron et al., 2017), unlike in other European countries such as the UK and Sweden where TMP alone remains available for medication purposes. Even if this factor alone is probably not sufficient to explain the non-detection of TMP in the most recent layers, this withdrawal may play a 
significant role. Moreover, the impact of wastewater treatment technologies may impact the removal of TMP and SMX differently as a monitoring study of the antibiotics' occurrence in the Seine River (Tamtam et al., 2008) revealed high concentrations of SMX ( 100 ng.L $\left.{ }^{-1}\right)$ and very limited concentrations of TMP $\left(<10 \mathrm{ng} . \mathrm{L}^{-1}\right)$, consistent with their sedimentary occurrences in the recent layers.

Regarding antibiotics, the maximum concentration of FLQ and OXO occurred in the middle 1980s, which is older than for most TrOCs. Both these antibiotics belong to the quinolone group, it is worth noting that the latter was progressively substituted by fluoroquinolones especially in human medicine (Figure S2), such as OFL, NOR and CIP (non-detected in this work) launched in 1985, 1986 and 1987, respectively (Zhanel et al., 2002).

Lastly, the distribution of TET is original and exhibited very significant concentrations. This molecule is heavily used in veterinary medicine, where its use represents more than $98 \%$ of the total use in France (Figure S2), and also displays a high affinity with solid matrices (Zhou et al., 2016). In several studies, tremendous amounts of TET were observed in livestock feces (e.g. $\sim 10 \mu g . g^{-1}$ in pig feces in Zhou et al. (Zhou et al., 2013)) at concentrations a hundred times higher than other antibiotics such as fluoroquinolones and sulfonamides. Also, in France, the use of tetracyclines largely exceeds the use of the other antibiotics detected in this work, especially for veterinary purposes (Figure S2). Therefore, this high use associated with high excretion and affinity with solid particles may be key factors in explaining these very significant concentrations of TET (Kuang et al., 2020). Moreover, livestock effluent management may directly impact the water quality in the absence of any treatment (Chiffre et al., 2016). The antibiotic loads of the effluents may be very high and contribute significantly to the total environmental loads of some veterinary antibiotics, such as TET (Jaffrézic et al., 2017).

Among pharmaceutical products, the most atypical pattern is displayed by COD, with very significant concentrations in the middle 1970s and no detection until this date. These erratic 
occurrences are largely impossible to explain, but were also observed in other sedimentary cores (Thiebault et al., 2017).

Finally, another atypical pattern is displayed by herbicides in general, and specifically ATR. This is one of the most frequently detected TrOCs in French water bodies due to its high mobility and persistency. It was widely used on maize and vineyard but also in urban areas with maximal application reported in the 80's in France. Then, uses slowly decreased due to lower maize areas and limited application rates from 3 to successively 1.5 kg.ha- in 1992 and 1 kg.ha${ }^{1}$ in 1997 before its ban in 2003 (Blanchoud et al., 2019). Furthermore, urban uses of ATR and SIM were restricted in 1998 due to high contamination of surface waters by direct runoff (Blanchoud et al., 2004). Yet, in the sampled cores, ATR occurrences were below the quantification limit between 2000 and 2003, and in addition, were the highest in the early 1980s, as for some other herbicides. This may reflect mostly an agricultural origin in the 1980s, and then, a mostly urban source until 1997. A precise knowledge of the sewer connectivity may confirm such assumption, but is unreachable. Some other pesticides were more recently banned to limit pesticide contamination like diuron (2003), CBD (2009) and ISO (2017), and new products are now in use like DFF and TEB, which were detected in the most recent layers.

\subsection{What can we learn from the historical distribution of TrOCs?}

The sedimentary occurrence of TrOCs is the result of several driving factors: (i) the use of the molecule in the watershed, (ii) the sewer connectivity (depending on the main source of the product), (iii) the wastewater treatment technology, (iv) the distance from the sources, (v) the physico-chemical properties of the targeted molecule and (vi) the sediment composition. As a result, a direct interpretation of a sedimentary occurrence into a historical use is somewhat speculative and requires a correct understanding of the contribution of each driving factor. 
In this work, the sedimentary composition varied weakly in the analyzed samples, as only a

439 slight decrease in the organic content, associated with an increase in the clay content was 440 observed between 1980 and 1990 (Figure 2). Such a small variation may not significantly impact the sorption of TrOCs. As the targeted molecules were in general intermediately hydrophilic/hydrophobic, a KOC normalization appeared unnecessary for a correct understanding of the vertical variations, unlike studies working on hydrophobic contaminants 444 (Alegria et al., 2016; Peters et al., 2020).

Another important driving factor may be the TrOC discharge in environmental compartments. Some of them are directly discharged in water bodies, without any treatment (e.g. pesticides, and some veterinary antibiotics), while for others, such as pharmaceuticals, the almost exclusive source is human consumption/excretion and discharge through wastewater effluents. For the latter TrOCs, the historical wastewater management and treatment technology is of great importance.

Lastly, the location of the core sampling is of prime importance as some contaminants are sparsely persistent in aquatic environments, especially amongst pharmaceutical products (Zhi et al., 2020). A previous study analyzed the occurrences of antibiotics in sediments of the same watershed, but $50 \mathrm{~km}$ upstream (Tamtam et al., 2011). In their study, the authors found a global increase in antibiotic concentrations until the late 1980s, since when a global decrease was observed. The same pattern was found in the present work for the three common molecules (SMX, FLQ, OXO). Yet, we have detected several antibiotics that were not detected in upstream sediments, such as NOR and TMP. It can therefore be assumed that the main drivers of the human-excreted TrOCs vertical distribution are the WWTP effluents nearby (E, GQ) rather than WWTP effluents farther upstream (i.e. SA) even if the former represent a much lower volume. 
This assumption is also validated by the decreasing concentrations of almost all TrOCs since 1996, the date at which the water treatment technology of WWTP E was significantly upgraded by the addition of a biological treatment (Figure 6). It can be considered that this supplementary treatment is more efficient than physico-chemical treatment alone for the removal of TrOCs (Joss et al., 2005; Petrie et al., 2014). Yet, no precise knowledge of the sewer connectivity prior to this date was available. Consequently, it is possible to discriminate the main sources of TrOCs only with this date, 1997. What is particularly interesting considering this key date is that beyond pharmaceuticals and most antibiotics, for which the main source is well-known to be wastewater effluents, several pesticides (e.g. ATR) also display decreasing concentrations since 1997. This can be attributed to the fact that pesticide occurrences in river waters result from a mix between agricultural and urban uses (i.e. between diffuse and point sources). Yet, several studies revealed that some pesticides (e.g. ATR, ISO) were more concentrated in the combined sewer systems of urban areas than in agricultural catchments (Paijens et al., 2021), even during the application period of these products (Wittmer et al., 2010). The urban contribution to the total pesticide contamination must therefore not be neglected, especially in an urban context where sediments were sampled close to the discharge of urban effluents. Therefore, counter to the claim made in a recent study dealing with lacustrine sediments in a less anthropized catchment (Chiaia-Hernández et al., 2020), in a more anthropized context, a proper understanding of the vertical variations of pesticides is challenging, because the distribution patterns were not expected. The only regular pattern was for CBD, whose concentrations have increased regularly since the 1970s. It is therefore possible that this molecule presents a more regular source than other pesticides, as agricultural use only for example.

\section{Conclusion}


This study assessed the sedimentary occurrences of TrOCs between 1944 and 2003 with an

487 almost yearly resolution. Various classes of contaminants, such as pesticides and 488 pharmaceutical products were evaluated. Their oldest occurrence was closely related to their

489

490

491

492

493

494

495

496

497

498

499

500

501

502

503

504

505 historical use, as the first occurrence of each TrOC was systematically later than the market authorization of the product, highlighting the contaminants’ preservation and their non-mobility within sedimentary layers and confirming their possible use as chronomarkers in sedimentary archives.

The picture is less straightforward, however, when looking at the vertical distribution of each molecule. In general, the highest occurrences were found during the 1980s, even if it is wellknown that the use of pharmaceutical products has dramatically increased since this date, which is validated by the increase in TrOC diversity in the most recent sediments. There is therefore an offset between the sedimentary occurrences of some TrOCs, and their use in the watershed. As the cores were sampled close to the discharge of one major WWTP, it can be considered that the evolution of sewage collection, and sewage treatment technology has dramatically modified the concentrations of TrOCs in surface waters, and in turn, their sedimentary occurrences. This is especially highlighted by the overall decrease in TrOC occurrences since the implementation of a biological treatment (i.e. for $\mathrm{N}$ and $\mathrm{P}$ removal) since 1997. Yet, other modifications (such as sewage collection improvement) were not recorded by the local authorities, making further assumptions about the occurrences of TrOCs in the older layers speculative.

Hence, this work provides some clues to the meaning of the vertical distribution of TrOCs from various classes in sedimentary environments. Further analyses remain necessary, however, in order to fully understand how historical sedimentary concentrations can be used beyond the use of the market authorization date. The possibility to sample new cores at the same site for the most recent period (i.e. since 2003) therefore represents a great potential for improving our 
this date.

\section{Acknowledgements}

This study was supported by the CONTORG project, funded by the UMR METIS. This work

also benefits from previous projects, supported by the Seine-Aval scientific research program.

\section{References}

Alegria, H., Martinez-Colon, M., Birgul, A., Brooks, G., Hanson, L., Kurt-Karakus, P., 2016. Historical sediment record and levels of PCBs in sediments and mangroves of Jobos Bay, Puerto Rico. Sci. Total Environ. 573, 1003-1009. https://doi.org/10.1016/j.scitotenv.2016.08.165

Al-Khazrajy, O.S.A., Boxall, A.B.A., 2016. Impacts of compound properties and sediment characteristics on the sorption behaviour of pharmaceuticals in aquatic systems. J. Hazard. Mater. 317, 198-209. https://doi.org/10.1016/j.jhazmat.2016.05.065

Altenburger, R., Ait-Aissa, S., Antczak, P., Backhaus, T., Barceló, D., Seiler, T.-B., Brion, F., Busch, W., Chipman, K., de Alda, M.L., de Aragão Umbuzeiro, G., Escher, B.I., Falciani, F., Faust, M., Focks, A., Hilscherova, K., Hollender, J., Hollert, H., Jäger, F., Jahnke, A., Kortenkamp, A., Krauss, M., Lemkine, G.F., Munthe, J., Neumann, S., Schymanski, E.L., Scrimshaw, M., Segner, H., Slobodnik, J., Smedes, F., Kughathas, S., Teodorovic, I., Tindall, A.J., Tollefsen, K.E., Walz, K.-H., Williams, T.D., Van den Brink, P.J., van Gils, J., Vrana, B., Zhang, X., Brack, W., 2015. Future water quality monitoring - Adapting tools to deal with mixtures of pollutants in water resource management. Sci. Total Environ. 512-513, 540-551. https://doi.org/10.1016/j.scitotenv.2014.12.057

Ayrault, S., Meybeck, M., Mouchel, J.-M., Gaspéri, J., Lestel, L., Lorgeoux, C., Boust, D., 2020. Sedimentary Archives Reveal the Concealed History of Micropollutant Contamination in the Seine River Basin, in: The Handbook of Environmental Chemistry. Springer, Berlin, Heidelberg, pp. 1-32. https://doi.org/10.1007/698_2019_386

Bernhardt, E.S., Rosi, E.J., Gessner, M.O., 2017. Synthetic chemicals as agents of global change. Front. Ecol. Environ. 15, 84-90. https://doi.org/10.1002/fee.1450

Blanchoud, H., Farrugia, F., Mouchel, J.M., 2004. Pesticide uses and transfers in urbanised catchments. Chemosphere 55, 905-913. https://doi.org/10.1016/j.chemosphere.2003.11.061

Blanchoud, H., Schott, C., Tallec, G., Queyrel, W., Gallois, N., Habets, F., Viennot, P., Ansart, P., Desportes, A., Tournebize, J., Puech, T., 2019. How Should Agricultural Practices Be Integrated to Understand and Simulate Long-Term Pesticide Contamination in the Seine River Basin?, in: The Handbook of Environmental Chemistry. Springer, Berlin, Heidelberg, pp. 122. https://doi.org/10.1007/698_2019_385

Botta, F., Lavison, G., Couturier, G., Alliot, F., Moreau-Guigon, E., Fauchon, N., Guery, B., Chevreuil, M., Blanchoud, H., 2009. Transfer of glyphosate and its degradate AMPA to surface waters through urban sewerage systems. Chemosphere 77, 133-139. https://doi.org/10.1016/j.chemosphere.2009.05.008

Caron, F., Wehrle, V., Etienne, M., 2017. The comeback of trimethoprim in France. Médecine Mal. Infect. 47, 253-260. https://doi.org/10.1016/j.medmal.2016.12.001 
Castro, O.G., Vale, C., 1995. Total PCB-organic matter correlation in sediments from three estuarine areas of Portugal. Netherland J. Aquat. Ecol. 29, 297-302. https://doi.org/10.1007/BF02084228

Chast, F., 2012. Histoire contemporaine des médicaments, La Découverte. ed. La Découverte, Paris.

Chauvel, B., Guillemin, J.-P., Gasquez, J., Gauvrit, C., 2012. History of chemical weeding from 1944 to 2011 in France: Changes and evolution of herbicide molecules. Crop Prot. 42, 320-326. https://doi.org/10.1016/j.cropro.2012.07.011

Chemspider Database, n.d. http:I/chemspider.com [WWW Document]. URL http://www.chemspider.com/ (accessed 5.16.19).

Chiaia-Hernández, A.C., Zander, P.D., Schneider, T., Szidat, S., Lloren, R., Grosjean, M., 2020. HighResolution Historical Record of Plant Protection Product Deposition Documented by Target and Nontarget Trend Analysis in a Swiss Lake under Anthropogenic Pressure. Environ. Sci. Technol. https://doi.org/10.1021/acs.est.0c04842

Chiffre, A., Degiorgi, F., Buleté, A., Spinner, L., Badot, P.-M., 2016. Occurrence of pharmaceuticals in WWTP effluents and their impact in a karstic rural catchment of Eastern France. Environ. Sci. Pollut. Res. 1-15. https://doi.org/10.1007/s11356-016-7751-5

Crossland, N.O., 1990. A review of the fate and toxicity of 3,4-dichloroaniline in aquatic environments. Chemosphere 21, 1489-1497. https://doi.org/10.1016/0045-6535(90)90054-W

da Silva, B.F., Jelic, A., López-Serna, R., Mozeto, A.A., Petrovic, M., Barceló, D., 2011. Occurrence and distribution of pharmaceuticals in surface water, suspended solids and sediments of the Ebro river basin, Spain. Chemosphere 85, 1331-1339. https://doi.org/10.1016/j.chemosphere.2011.07.051

Daughton, C.G., 2004. Non-regulated water contaminants: emerging research. Environ. Impact Assess. Rev., Environment and Health: new answers, new questions. 24, 711-732. https://doi.org/10.1016/j.eiar.2004.06.003

De Feo, G., Antoniou, G., Fardin, H.F., El-Gohary, F., Zheng, X.Y., Reklaityte, I., Butler, D., Yannopoulos, S., Angelakis, A.N., 2014. The Historical Development of Sewers Worldwide. Sustainability 6, 3936-3974. https://doi.org/10.3390/su6063936

Dendievel, A.-M., Mourier, B., Coynel, A., Evrard, O., Labadie, P., Ayrault, S., Debret, M., Koltalo, F., Copard, Y., Faivre, Q., Gardes, T., Vauclin, S., Budzinski, H., Grosbois, C., Winiarski, T., Desmet, M., 2020. Spatio-temporal assessment of the polychlorinated biphenyl (PCB) sediment contamination in four major French river corridors (1945-2018). Earth Syst. Sci. Data 12, 1153-1170. https://doi.org/10.5194/essd-12-1153-2020

European Commission, 2000. Directive 2000/60/EC of the European Parliament and of the Council of 23 October 2000 establishing a framework for Community action in the field of water policy. Off. J Eur. Union L327 1-77.

European Commission, 1991a. Directive 91/414/EEC concerning the placing of plant protection products on the market. Off. J Eur. Union L230 20.

European Commission, 1991b. Directive 91/271/CEE of the Council of 21 May 1991, related to Urban Waste Water Treatment. Off. J Eur. Union L135 40-52.

Fuller, C.C., van Geen, A., Baskaran, M., Anima, R., 1999. Sediment chronology in San Francisco Bay, California, defined by 210Pb, 234Th, 137Cs, and 239,240Pu. Mar. Chem. 64, 7-27. https://doi.org/10.1016/S0304-4203(98)00081-4

Garrison, A.W., Pope, J.D., Allen, F.R., Keith, L.H., 1976. GC/MS analysis of organic compounds in domestic wastewaters, in: Identification and Analysis of Organic Pollutants in Water. Ann Arbor Science Publishers, Ann Arbor, MI, pp. 517-556.

Gatidou, G., Kotrikla, A., Thomaidis, N.S., Lekkas, T.D., 2004. Determination of two antifouling booster biocides and their degradation products in marine sediments by high performance liquid chromatography-diode array detection. Anal. Chim. Acta, Papers presented at the 3rd Aegean Analytical Chemistry Days 505, 153-159. https://doi.org/10.1016/S00032670(03)00412-4

Hara, K., Kuroda, M., Yabar, H., Kimura, M., Uwasu, M., 2016. Historical development of wastewater and sewage sludge treatment technologies in Japan - An analysis of patent data from the past 50 years. Environ. Dev. 19, 59-69. https://doi.org/10.1016/j.envdev.2016.05.001 
Hignite, C., Azarnoff, D.L., 1977. Drugs and drug metabolites as environmental contaminants: chlorophenoxyisobutyrate and salicyclic acid in sewage water effluent. Life Sci. 20, 337-341. https://doi.org/10.1016/0024-3205(77)90329-0

Jaffrézic, A., Jardé, E., Soulier, A., Carrera, L., Marengue, E., Cailleau, A., Le Bot, B., 2017. Veterinary pharmaceutical contamination in mixed land use watersheds: from agricultural headwater to water monitoring watershed. Sci. Total Environ. 609, 992-1000. https://doi.org/10.1016/j.scitotenv.2017.07.206

Joss, A., Keller, E., Alder, A.C., Göbel, A., McArdell, C.S., Ternes, T., Siegrist, H., 2005. Removal of pharmaceuticals and fragrances in biological wastewater treatment. Water Res. 39, 31393152. https://doi.org/10.1016/j.watres.2005.05.031

Kaci, A., Petit, F., Fournier, M., Cécillon, S., Boust, D., Lesueur, P., Berthe, T., 2016. Diversity of active microbial communities subjected to long-term exposure to chemical contaminants along a 40-year-old sediment core. Environ. Sci. Pollut. Res. 23, 4095-4110. https://doi.org/10.1007/s11356-015-4506-7

Kaci, A., Petit, F., Lesueur, P., Boust, D., Vrel, A., Berthe, T., 2014. Distinct diversity of the czcA gene in two sedimentary horizons from a contaminated estuarine core. Environ. Sci. Pollut. Res. 21, 10787-10802. https://doi.org/10.1007/s11356-014-3029-y

Keil, R.G., Montlucon, D.B., Prahli, F.G., 1994. Sorptive preservation of labile organic matter in marine sediments. Nature 370, 18. https://doi.org/10.1038/370549a0

Kerrigan, J.F., Sandberg, K.D., Engstrom, D.R., LaPara, T.M., Arnold, W.A., 2018. Sedimentary record of antibiotic accumulation in Minnesota Lakes. Sci. Total Environ. 621, 970-979. https://doi.org/10.1016/j.scitotenv.2017.10.130

Klaminder, J., Brodin, T., Sundelin, A., Anderson, N.J., Fahlman, J., Jonsson, M., Fick, J., 2015. Long-term persistence of an anxiolytic drug (oxazepam) in a large freshwater lake. Environ. Sci. Technol. 49, 10406-10412. https://doi.org/10.1021/acs.est.5b01968

Kodešová, R., Grabic, R., Kočárek, M., Klement, A., Golovko, O., Fér, M., Nikodem, A., Jakšík, O., 2015. Pharmaceuticals' sorptions relative to properties of thirteen different soils. Sci. Total Environ. 511, 435-443. https://doi.org/10.1016/j.scitotenv.2014.12.088

Kuang, Y., Guo, X., Hu, J., Li, S., Zhang, R., Gao, Q., Yang, X., Chen, Q., Sun, W., 2020. Occurrence and risks of antibiotics in an urban river in northeastern Tibetan Plateau. Sci. Rep. 10, 20054. https://doi.org/10.1038/s41598-020-77152-5

Lahti, M., Oikari, A., 2012. Vertical distribution of pharmaceuticals in lake sediments—citalopram as potential chemomarker. Environ. Toxicol. Chem. 31, 1738-1744. https://doi.org/10.1002/etc.1901

Lara-Martín, P.A., Renfro, A.A., Cochran, J.K., Brownawell, B.J., 2015. Geochronologies of Pharmaceuticals in a Sewage-Impacted Estuarine Urban Setting (Jamaica Bay, New York). Environ. Sci. Technol. 49, 5948-5955. https://doi.org/10.1021/es506009v

Loos, R., Carvalho, R., António, D.C., Comero, S., Locoro, G., Tavazzi, S., Paracchini, B., Ghiani, M., Lettieri, T., Blaha, L., Jarosova, B., Voorspoels, S., Servaes, K., Haglund, P., Fick, J., Lindberg, R.H., Schwesig, D., Gawlik, B.M., 2013. EU-wide monitoring survey on emerging polar organic contaminants in wastewater treatment plant effluents. Water Res. 47, 64756487. https://doi.org/10.1016/j.watres.2013.08.024

Loos, R., Gawlik, B.M., Locoro, G., Rimaviciute, E., Contini, S., Bidoglio, G., 2009. EU-wide survey of polar organic persistent pollutants in European river waters. Environ. Pollut. 157, 561-568. https://doi.org/10.1016/j.envpol.2008.09.020

McCance, W., Jones, O.A.H., Edwards, M., Surapaneni, A., Chadalavada, S., Currell, M., 2018. Contaminants of Emerging Concern as novel groundwater tracers for delineating wastewater impacts in urban and peri-urban areas. Water Res. 146, 118-133. https://doi.org/10.1016/j.watres.2018.09.013

Paijens, C., Bressy, A., Frère, B., Tedoldi, D., Mailler, R., Rocher, V., Neveu, P., Moilleron, R., 2021. Urban pathways of biocides towards surface waters during dry and wet weathers: Assessment at the Paris conurbation scale. J. Hazard. Mater. 402, 123765. https://doi.org/10.1016/j.jhazmat.2020.123765

Peters, L.I., Rose, N.L., Yang, H., Klánová, J., Moehring, T., Harrad, S., 2020. Temporal Trends in Radiometrically Dated Sediment Cores from English Lakes Show Polybrominated Diphenyl 
Ethers Correlate with Brominated but not Mixed Bromo/Chloro Dioxins and Furans. Sci. Total Environ. 143118. https://doi.org/10.1016/j.scitotenv.2020.143118

Petrie, B., McAdam, E.J., Lester, J.N., Cartmell, E., 2014. Obtaining process mass balances of pharmaceuticals and triclosan to determine their fate during wastewater treatment. Sci. Total Environ. 497-498, 553-560. https://doi.org/10.1016/j.scitotenv.2014.08.003

Robeck, G.G., Dostal, K.A., Cohen, J.M., Kreissl, J.F., 1965. Effectiveness of Water Treatment Processes in Pesticide Removal. J. AWWA 57, 181-199. https://doi.org/10.1002/j.15518833.1965.tb01386.x

Rocher, V., Azimi, S., Syndicat interdépartemental pour l'assainissement de l'agglomération parisienne, 2017. Evolution de la qualité de la Seine en lien avec les progrès de l'assainissement de 1970 à 2015, Johanet. ed. Paris.

Salter, A.J., 1982. Overview. Trimethoprim-Sulfamethoxazole: An Assessment of More than 12 Years of Use. Rev. Infect. Dis. 4, 196-236. https://doi.org/10.1093/clinids/4.2.196

Santschi, P.H., Presley, B.J., Wade, T.L., Garcia-Romero, B., Baskaran, M., 2001. Historical contamination of PAHs, PCBs, DDTs, and heavy metals in Mississippi River Delta, Galveston Bay and Tampa Bay sediment cores. Mar. Environ. Res. 52, 51-79. https://doi.org/10.1016/S0141-1136(00)00260-9

Stein, K., Ramil, M., Fink, G., Sander, M., Ternes, T.A., 2008. Analysis and sorption of psychoactive drugs onto sediment. Environ. Sci. Technol. 42, 6415-6423. https://doi.org/10.1021/es702959a

Tamtam, F., Le Bot, B., Dinh, T., Mompelat, S., Eurin, J., Chevreuil, M., Bonté, P., Mouchel, J.-M., Ayrault, S., 2011. A 50-year record of quinolone and sulphonamide antimicrobial agents in Seine River sediments. J. Soils Sediments 11, 852-859. https://doi.org/10.1007/s11368-0110364-1

Tamtam, F., Mercier, F., Le Bot, B., Eurin, J., Tuc Dinh, Q., Clément, M., Chevreuil, M., 2008. Occurrence and fate of antibiotics in the Seine River in various hydrological conditions. Sci. Total Environ. 393, 84-95. https://doi.org/10.1016/j.scitotenv.2007.12.009

Thiebault, T., 2020. Sulfamethoxazole/Trimethoprim ratio as a new marker in raw wastewaters: A critical review. Sci. Total Environ. 715, 136916. https://doi.org/10.1016/j.scitotenv.2020.136916

Thiebault, T., Chassiot, L., Fougère, L., Destandau, E., Simonneau, A., Van Beek, P., Souhaut, M., Chapron, E., 2017. Record of pharmaceutical products in river sediments: A powerful tool to assess the environmental impact of urban management? Anthropocene 18, 47-56. https://doi.org/10.1016/j.ancene.2017.05.006

Tinti, A., Tugnoli, V., Bonora, S., Francioso, O., 2015. Recent applications of vibrational mid-Infrared (IR) spectroscopy for studying soil components: a review. J. Cent. Eur. Agric. 16, 0-0. https://doi.org/10.5513/JCEA01/16.1.1535

Tran, N.H., Reinhard, M., Khan, E., Chen, H., Nguyen, V.T., Li, Y., Goh, S.G., Nguyen, Q.B., Saeidi, N., Gin, K.Y.-H., 2019. Emerging contaminants in wastewater, stormwater runoff, and surface water: Application as chemical markers for diffuse sources. Sci. Total Environ. 676, 252-267. https://doi.org/10.1016/j.scitotenv.2019.04.160

Välitalo, P., Kruglova, A., Mikola, A., Vahala, R., 2017. Toxicological impacts of antibiotics on aquatic micro-organisms: A mini-review. Int. J. Hyg. Environ. Health, Special Issue: Eighth PhD students workshop: Water and Health - Cannes 2016 220, 558-569. https://doi.org/10.1016/j.ijheh.2017.02.003

Verlicchi, P., Al Aukidy, M., Zambello, E., 2012. Occurrence of pharmaceutical compounds in urban wastewater: Removal, mass load and environmental risk after a secondary treatment-A review. Sci. Total Environ. 429, 123-155. https://doi.org/10.1016/j.scitotenv.2012.04.028

Vrel, A., Boust, D., Lesueur, P., Deloffre, J., Dubrulle-Brunaud, C., Solier, L., Rozet, M., Thouroude, C., Cossonnet, C., Thomas, S., 2013. Dating of sediment record at two contrasting sites of the Seine River using radioactivity data and hydrological time series. J. Environ. Radioact. 126, 20-31. https://doi.org/10.1016/j.jenvrad.2013.06.005

Wittmer, I.K., Bader, H.-P., Scheidegger, R., Singer, H., Lück, A., Hanke, I., Carlsson, C., Stamm, C., 2010. Significance of urban and agricultural land use for biocide and pesticide dynamics in surface waters. Water Res. 44, 2850-2862. https://doi.org/10.1016/j.watres.2010.01.030 
Zgheib, S., Moilleron, R., Chebbo, G., 2012. Priority pollutants in urban stormwater: Part 1 - Case of separate storm sewers. Water Res., Special Issue on Stormwater in urban areas 46, 66836692. https://doi.org/10.1016/j.watres.2011.12.012

Zhanel, G.G., Ennis, K., Vercaigne, L., Walkty, A., Gin, A.S., Embil, J., Smith, H., Hoban, D.J., 2002. A Critical Review of the Fluoroquinolones. Drugs 62, 13-59. https://doi.org/10.2165/00003495-200262010-00002

Zhi, H., Kolpin, D.W., Klaper, R.D., Iwanowicz, L.R., Meppelink, S.M., LeFevre, G.H., 2020. Occurrence and Spatiotemporal Dynamics of Pharmaceuticals in a Temperate-Region Wastewater Effluent-Dominated Stream: Variable Inputs and Differential Attenuation Yield Evolving Complex Exposure Mixtures. Environ. Sci. Technol. 54, 12967-12978. https://doi.org/10.1021/acs.est.0c02328

Zhou, J., Broodbank, N., 2014. Sediment-water interactions of pharmaceutical residues in the river environment. Water Res. 48, 61-70. https://doi.org/10.1016/j.watres.2013.09.026

Zhou, L.-J., Wu, Q.L., Zhang, B.-B., Zhao, Y.-G., Zhao, B.-Y., 2016. Occurrence, spatiotemporal distribution, mass balance and ecological risks of antibiotics in subtropical shallow Lake Taihu, China. Environ. Sci. Process. Impacts. https://doi.org/10.1039/C6EM00062B

Zhou, L.-J., Ying, G.-G., Liu, S., Zhao, J.-L., Yang, B., Chen, Z.-F., Lai, H.-J., 2013. Occurrence and fate of eleven classes of antibiotics in two typical wastewater treatment plants in South China. Sci. Total Environ. 452, 365-376. https://doi.org/10.1016/j.scitotenv.2013.03.010 